\title{
Novel $\mathrm{SO}_{2}$ spectral evaluation scheme using the $360-390 \mathrm{~nm}$ wavelength range
}

\author{
N. Bobrowski ${ }^{1}$, C. Kern ${ }^{1}$, U. Platt ${ }^{1}$, C. Hörmann ${ }^{1,2}$, and T. Wagner ${ }^{2}$ \\ ${ }^{1}$ Institut for Environmental Physics, University of Heidelberg, Heidelberg, Germany \\ ${ }^{2}$ Max Planck Institute for Chemistry, Satellite Remote Sensing, Mainz, Germany
}

Received: 13 January 2010 - Published in Atmos. Meas. Tech. Discuss.: 3 March 2010

Revised: 12 June 2010 - Accepted: 21 June 2010 - Published: 8 July 2010

\begin{abstract}
Differential Optical Absorption Spectroscopy (DOAS) is a well established spectroscopic method to determine trace gases in the atmosphere. During the last decade, passive DOAS, which uses solar radiation scattered in the atmosphere as a light source, has become a standard tool to determine $\mathrm{SO}_{2}$ column densities and emission fluxes from volcanoes and other large sources by ground based as well as satellite measurements. For the determination of $\mathrm{SO}_{2}$ column densities, the structured absorption of the molecule in the $300-330 \mathrm{~nm}$ region (due to the $\mathrm{A}^{1} \mathrm{~B}_{1} \leftarrow \mathrm{X}^{1} \mathrm{~A}_{1}$ transition) is used. However, there are several problems limiting the accuracy of the technique in this particular application. Here we propose to use an alternative wavelength region (360$390 \mathrm{~nm}$ ) due to the spin-forbidden $\mathrm{a}^{3} \mathrm{~B}_{2} \leftarrow \mathrm{X}^{1} \mathrm{~A}_{1}$ transition for the DOAS evaluation of $\mathrm{SO}_{2}$ in conditions where high $\mathrm{SO}_{2}$ column densities prevail. We show this range to have considerable advantages in such cases, in particular when the particle content of the plume is high and when measurements are performed at large distances from the area of interest.
\end{abstract}

\section{Introduction}

Sulphur influences atmospheric chemistry as well as climate and can negatively affect our health. It has been known for a long time that sulphur species are naturally released to the atmosphere through volcanism (mainly as $\mathrm{SO}_{2}$ and $\mathrm{H}_{2} \mathrm{~S}$ ) or biological processes - decay of organic matter $\left(\mathrm{H}_{2} \mathrm{~S}, \mathrm{CH}_{3} \mathrm{SH}\right.$ or $\mathrm{CH}_{3} \mathrm{SCH}_{3}$ ) and sea spray (sulphate). Since the Industrialization anthropogenic sources have increased and have been comparable in magnitude to natural ones since the early 20th century.

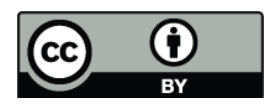

Correspondence to: N. Bobrowski (n.bobrowski@iup.uni-heidelberg.de)
Sulphur aerosol affects the radiation balance of the atmosphere directly (i.e. cooling by sulphate particles) and indirectly by acting as cloud condensation nuclei $(\mathrm{CCN}) . \mathrm{SO}_{2}$, $\mathrm{SO}_{3}, \mathrm{H}_{2} \mathrm{SO}_{4}$ are aerosol precursors, which lead to cloud formation and serve as surfaces for heterogeneous chemistry. The modification of the cloud properties by sulfate aerosol is associated with a cooling effect (e.g. Lohmann and Feichter, 2005). The sulphur particles enhance the number of aerosols and therefore increase the albedo. The result is a reduction of the direct incoming solar radiation.

Since the eruption of El Chichon 1982 when $\mathrm{SO}_{2}$ was detected by satellite measurements for the first time through the Total Ozone Mapping Spectrometer (TOMS) on the Nimbus7 satellite (Krueger, 1983) and later, the algorithms and instruments to detect $\mathrm{SO}_{2}$ from space are under continuous improvement (e.g. Eisinger and Burrows, 1998; Khokar et al., 2005; Krotkov et al., 2006; Lee et al., 2008; Krueger et al., 1995, 2008)

Developed since the mid-seventies (Noxon, 1975; Perner et al., 1976; Platt et al., 1979), today DOAS is a well established spectroscopic method to determine trace gases in the atmosphere, among others also $\mathrm{SO}_{2}$. DOAS is typically applied in the UV-visible wavelength region and uses the narrow band absorption features of molecules for their identification; a detailed description can e.g. be found in Platt and Stutz (2008). During the last decade, the passive DOAS technique, which uses solar radiation scattered in the atmosphere as a light source (see e.g. Hönninger et al., 2004a; Platt and Stutz, 2008), has become a standard tool to determine $\mathrm{SO}_{2}$ emission fluxes from volcanoes world wide (e.g. Galle et al., 2003, 2009; Horton et al., 2006; McGonigle, 2007) and has started to replace the Correlation Spectroscopy (COSPEC) developed in the 1960ties, (e.g. Millan et al., 1969). Moreover, DOAS offers the possibility to analyse for other volcanic gases, like BrO (see e.g. Bobrowski et al., 2003), as well. This was possible due to the technological development of cheaper and smaller spectrometers, sensitive and fast

Published by Copernicus Publications on behalf of the European Geosciences Union. 
multi-channel array detectors, powerful computers, and efficient algorithms for the analysis of differential absorption spectra.

The DOAS method is usually applied to weak absorbers with optical densities below approximately 0.05 (an exception are retrievals of stratospheric $\mathrm{O}_{3}$ (e.g. Solomon et al., 1987). However, when measuring $\mathrm{SO}_{2}$ absorption in volcanic plumes and considering the commonly used evaluation range between 300 and $325 \mathrm{~nm}$, optical densities can exceed unity. Such strong absorbers can complicate the DOAS retrieval algorithm when using high resolution reference spectra from literature, which have to be convoluted with the instrumental line-shape of the employed spectrometer. This well known phenomenon (see e.g. Volkamer et al., 1998; Platt and Stutz, 2008; Kern, 2009) is caused by a non-linearity in the relationship between the measured optical density and the column density occurring at high optical densities when the spectral resolution of the instrument is insufficient to fully resolve the absorption bands, as is usually the case with the compact spectrometers employed for volcanic surveillance. The problem can be solved by using an iterative approach like the Iterative Maximum A Posteriori DOAS technique (IMAP-DOAS, see Frankenberg et al., 2005 for more detailed information), but such methods require high computation power and are rarely applied today.

A further problem associated with the commonly evaluated wavelength range below $330 \mathrm{~nm}$, where the strong absorptions due to the $\mathrm{A}^{1} \mathrm{~B}_{1} \leftarrow \mathrm{X}^{1} \mathrm{~A}_{1}$ transition of the $\mathrm{SO}_{2}$ molecule are located, is caused by the rather low intensity of scattered sunlight (mostly due to ozone absorption in the stratosphere) and therefore unfavourably high photon shot noise. Additionally for this UV wavelength region where the measured intensities are generally low, compared to the longer wavelength UV also entering the instrument, straylight can contribute a significant fraction of the measured signal, leading to a considerable underestimation for the true optical density. This is particularly severe for the frequently applied compact spectrometers (e.g. from Ocean Optics). Correction of this effect is not at all straightforward (Van Roozendael et al., 2006).

Two other spectroscopic issues can potentially lead to minor errors in the evaluation. For one, the $\mathrm{SO}_{2}$ absorption cross section is slightly dependent on temperature thus leading to an imperfect fit if the temperature of the measured gas deviates from the temperature at which the cross-section was measured. Secondly, the $\mathrm{O}_{3}$ absorption in the lower part of the $\mathrm{SO}_{2}$ evaluation wavelength range can be sufficiently strong to interfere with the $\mathrm{SO}_{2}$ evaluation. Both of these effects are however usually of subordinate importance compared to the other spectroscopic errors mentioned above.

Apart from the above mentioned spectroscopic issues, it has only recently been shown that the accuracy of remote sensing techniques measuring volcanic $\mathrm{SO}_{2}$ in the UVvisible wavelength region using scattered solar radiation as a light source is often largely dependent on our knowledge of the radiative transfer in and around the measured volcanic plume (Kern et al., 2010). The results show that this especially applies to situations in which $\mathrm{SO}_{2}$ is a strong absorber, as the optical path of incident radiation is significantly influenced by absorption in the plume in such cases. There are three problems related to radiation transport:

- Radiation is scattered in the atmosphere both, by air molecules (mostly Rayleigh scattering) and by aerosol particles. While aerosol scattering is only weakly dependent on the wavelength $\lambda$ (approximately proportional to $\lambda^{-1.3}$ ), Rayleigh scattering is proportional to $\lambda^{-4}$. This fact leads to a wavelength dependent mean free photon path in the atmosphere. Photons of shorter wavelengths travel significantly shorter mean paths between scattering events than photons of longer wavelengths. Thus, radiation of shorter wavelengths is more likely to be scattered between instrument and plume than radiation of longer wavelengths. This socalled "radiation dilution" effect was already discussed in Moffat and Millan (1971) and modelled by Millan (1980), but in ground based DOAS measurements first observed by Mori et al. (2006), who realized that the $\mathrm{SO}_{2}$ column density $(\mathrm{CD})$ retrieved from measured spectra depended on the wavelength range in which the evaluation took place. Especially for long distances between instrument and plume (i.e. several $\mathrm{km}$ ), evaluations at shorter wavelengths yielded lower $\mathrm{SO}_{2}$ column densities than those performed at longer wavelengths. The same effect is known and has frequently been discussed in the satellite community since about a decade (e.g. Palmer et al., 2001; Richter and Burrows, 2002; Eskes et al., 2003) and appropriate suggestions how to correct it have been made.

- Aside from the reduction of the apparent $\mathrm{SO}_{2} \mathrm{CD}$ due to radiation dilution, multiple scattering inside the plume can also enhance the $\mathrm{SO}_{2} \mathrm{CD}$. Depending on the particular situation (i.e. amount and properties of aerosols in the plume and in the air surrounding the plume), the enhancement of the effective photon path due to multiple scattering can be of the same order of magnitude as the above described dilution. Therefore, the measured CD can be either over- or underestimated in any particular measurement.

- In cases of strong absorption, the observed scattered light has only penetrated the outermost layers of the $\mathrm{SO}_{2}$ plume. In extreme cases, the sensitivity for the whole plume can become essentially zero (AMF $\sim 0$ leading to a strong underestimation of the true $\mathrm{CD}$ ), because at the wavelength where the $\mathrm{SO}_{2}$ absorptions are observed the plume is completely dark. In reality, this effect is, however, typically reduced due to the presence of aerosols, and a small fraction of the observed 
light is scattered by aerosols inside the plume. Then the $\mathrm{SO}_{2}$ absorption signal is still weak but not zero.

In fact, the effect that not all of the detected radiation has passed through the region of interest in a straight line is a well known issue in optical remote sensing. Typically, the concept of air mass factor (AMF) is used to describe the phenomenon. The AMF gives the ratio of the measured column density to the theoretical column density along a straight line through the region of interest (see Kern et al. 2010 for a more specific definition). Therefore, an AMF of less than unity indicates that the average light path inside the region of interest (in this case the volcanic plume) is shorter than the column along a straight path through the plume.

In principle these effects could be corrected for using modified DOAS approaches (e.g. Marquard et al., 2000). However, especially for very strong absorptions not only the total optical depth but also the profile shape becomes important preventing a simple parameterisation of the correction. In extreme cases the observation might become even completely insensitive for the lowest part of the $\mathrm{SO}_{2}$ plume.

Previous attempts have been made to correct for the nonlinearity of $\mathrm{SO}_{2}$ absorptions as a function of wavelength (e.g. Yang et al., 2007), especially in the case of rather high $\mathrm{SO}_{2}$ concentrations. The AMF in the standard fit range $(<320 \mathrm{~nm})$ strongly depends on wavelength, leading to an underestimation of the regarded $\mathrm{SO}_{2}$ amount. In order to account for these effects, an iterative model approach can be applied (see Yang et al., 2009; Richter et al., 2009). As such iterative model calculations are rather time intensive, switching to an fit window at longer wavelength where the response to enhanced $\mathrm{SO}_{2}$ concentrations is more linear (respectively the AMF), is a sufficient and particularly fast method to correct for the occurring non-linear effects (Yang et al., 2007).

Here we propose a new approach to the problem using an alternative wavelength region for the DOAS evaluation of $\mathrm{SO}_{2}$, which can have considerable advantages under certain conditions, in particular when high $\mathrm{SO}_{2}$ column densities prevail or when measurements at large distances from the area of interest are necessary.

\section{The new approach}

In cases of high $\mathrm{SO}_{2}$ column densities, the relatively weak system of absorption lines corresponding to the spinforbidden $\mathrm{a}^{3} \mathrm{~B}_{2} \leftarrow \mathrm{X}^{1} \mathrm{~A}_{1}$ transition of the $\mathrm{SO}_{2}$ molecule can be used to quantitatively detect this species. Compared to the standard evaluation range of approximately 310 to $325 \mathrm{~nm}$ (due to the $\mathrm{A}^{1} \mathrm{~B}_{1} \leftarrow \mathrm{X}^{1} \mathrm{~A}_{1}$ transition), which has been used by all hitherto reported UV-spectroscopic $\mathrm{SO}_{2}$ measurements, the absorption lines of this system are found in the longer UV wavelength region of about 350 to $390 \mathrm{~nm}$, which can have a number of advantages. In the following we refer to the two evaluation windows as the "long wave UV" and "short wave UV" windows, respectively (see Fig. 4). The differential absorption cross section of $\mathrm{SO}_{2}$ is about two to three orders of magnitude lower in the long wave UV window, therefore the above mentioned problems of nonlinearity are avoided. While the weaker absorption cross section also leads to a lower sensitivity for $\mathrm{SO}_{2}$, this effect is in part compensated by a higher light intensity at longer wavelengths, which leads to considerably better signal/noise ratios. In the following, two examples of the $\mathrm{SO}_{2}$ evaluation in the proposed long wave UV window of 360-390 nm are presented in comparison to an evaluation between 315 and $325 \mathrm{~nm}$. As one example, we discuss a spectrum recorded by a ground based instrument at Mt. Etna Volcano in June 2008, as the other we report satellite measurements of the eruption of Kasatochi volcano in August 2008.

Also a theoretical model study was performed, which investigates the influence of radiation dilution on remote sensing measurements in the proposed long wave UV wavelength region around $375 \mathrm{~nm}$ in comparison to the standard range around $320 \mathrm{~nm}$ using the backward Monte-Carlo radiative transfer model McArtim (Deutschmann, 2008) to simulate the propagation of radiation between the sun and a simulated instrument located on the ground at various distances from the volcanic plume or of the backscattered sun-light to a satellite instrument. The results show that the transition from short wave UV to long wave UV leads to a decrease in the radiation dilution effect, and that the AMF is typically closer to unity for the new retrieval window if the distance between instrument and plume is larger than approximately $1 \mathrm{~km}$. Also in the case of satellite remote sensing, the new proposed fit region prevents underestimation of $\mathrm{SO}_{2}$ column densities in cases of high $\mathrm{SO}_{2}$ loads.

\section{Sample measurements and evaluations in the short wave UV and long wave UV windows}

\subsection{Ground based measurement example}

For the ground based measurement example, a Miniature MultiAxis-DOAS (Mini-MAX-DOAS) instrument (described in detail e.g. by Hönninger et al. (2004b); Bobrowski et al. (2007); Bobrowski and Platt (2007)) was set up on the North East crater rim of Mt. Etna volcano (Italy) on 10 June 2008. The miniaturised MAX-DOAS system consists of an airtight aluminium box containing a temperature stabilized commercial miniature spectrometer (OceanOptics Inc., USB2000) covering the spectral range from $289 \mathrm{~nm}$ to $442 \mathrm{~nm}$, a small telescope (fused silica lens, $f=40 \mathrm{~mm}$, $d=20 \mathrm{~mm}$, field of view approximately $0.6^{\circ}$ ) coupled to the spectrometer by a quartz fibre bundle (4 fibres with $200 \mu \mathrm{m}$ core diameter), and electronics for temperature regulation and stepper motor control. A geared stepper motor is attached to one side of the box and turns it to point the telescope at different elevation angles between 0 and 

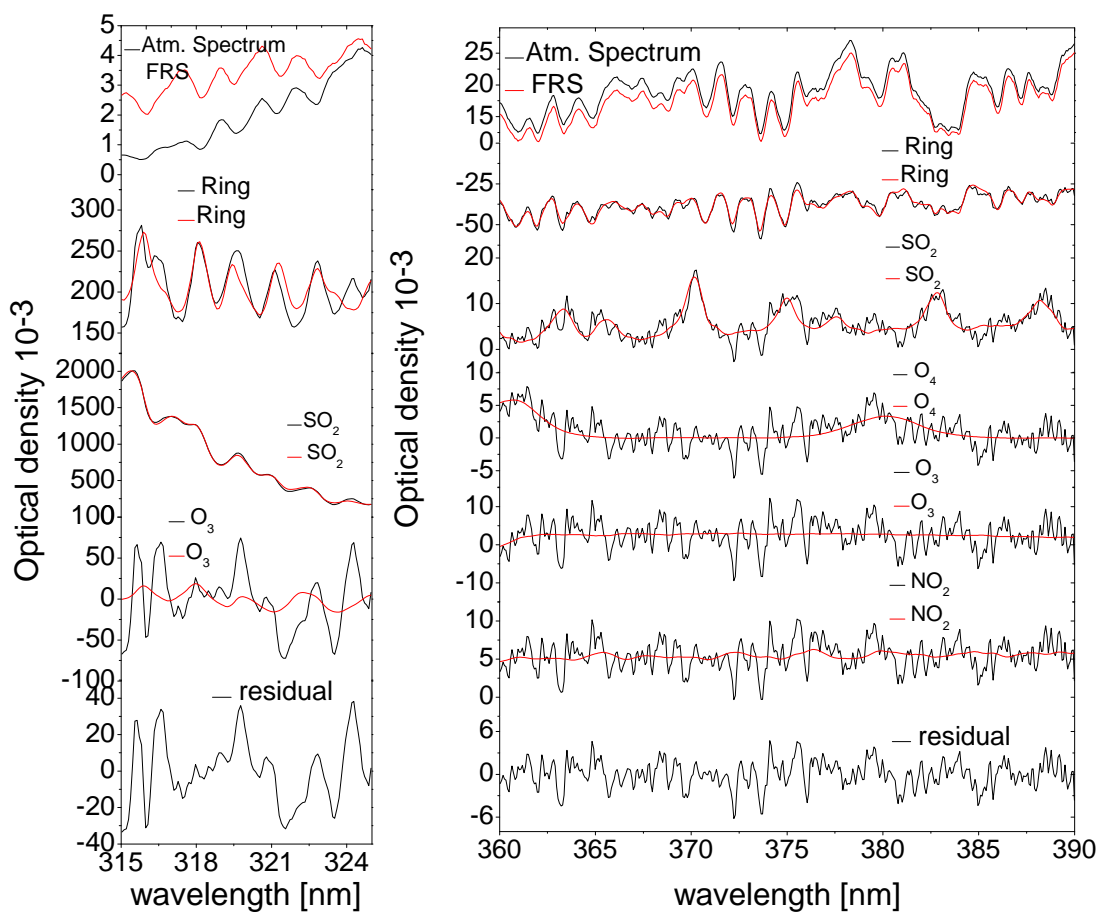

Fig. 1. Example of the DOAS $\mathrm{SO}_{2}$-Fit. Black lines: measured spectra, red lines: reference spectra, the atmospheric spectrum was taken inside the volcanic cloud of Etna $\left(\alpha=9^{\circ}\right)$ on 10 June 2008 at 11:22 local time (a) evaluation in the short wave UV window 315-325 nm (b) evaluation in the long wave UV window $360-390 \mathrm{~nm}$.

150 degrees. Automatic data acquisition was performed by the DOASIS software package (Kraus et al., 2001) running on a notebook computer. The distance to the volcanic plume was about $100 \mathrm{~m}$. The plume visually had a white appearance, probably caused by the large amount of condensation of emitted water vapour. Aside from the plume, a cloudless sky was observed.

The wavelengths to pixel mapping (WPM) as well as the instrumental line shape (instrument function) were determined by taking a spectrum of a low-pressure mercury emission lamp. By using the known mercury spectral line positions, a second order polynomial describing the WPM was calculated. The WPM was later adjusted using the Fraunhofer structure of the measured spectra compared to a literature solar emission spectrum (Kurucz et al., 1984).

The software WinDoas V2.10 from IASB (Belgium Institute for Space Aeronomy, (Fayt and Van Roozendael, 2001) was used to derive the slant column densities (SCD) of $\mathrm{SO}_{2}$ from the recorded spectra using a standard DOAS fit. A background spectrum recorded shortly after each plume measurement was taken as a Fraunhofer reference spectrum (FRS) to remove the Fraunhofer lines. Care was taken to avoid absorption structures of volcanic species in the FRS. All measured spectra were corrected for spectrometer stray light by subtracting a constant offset in such a way as to force the intensity measured below $298 \mathrm{~nm}$, where ozone absorption is sufficiently large to block all incident solar radiation, to zero. In addition, a "Ring" spectrum was calculated to compensate for the effect of Raman scattering in the atmosphere (Bussemer, 1993).

$\mathrm{SO}_{2}$ was first analyzed in the typical short wave UV region of 315 to $325 \mathrm{~nm}$. Apart from the $\mathrm{SO}_{2}$ reference spectrum (Bogumil et al., 2003, $-293 \mathrm{~K}$ ), two $\mathrm{O}_{3}$ reference spectra measured at 223 and $246 \mathrm{~K}$ (Voigt et al., 2001), a Ring spectrum (to remove artefacts caused by inelastic scattering in the atmosphere (Ring effect, see Bussemer, 1993) and the Fraunhofer reference spectrum were included in the fitting process. A 3rd order polynomial was applied to remove broad-band structures, and a shift and 1st order squeeze were allowed for the measured spectra to compensate possible wavelength calibration errors.

A sample evaluation result is shown in Fig. 1a. The $\mathrm{SO}_{2}$ absorption features are easily detectable, but several unexplained structures remain in the residual spectrum, with fairly high amplitudes $\left(2.7 \times 10^{-2} \mathrm{RMS}\right)$ and features that do not appear to be randomly distributed (as would be expected of pure noise). Also, the Ring spectrum is not very well captured by the fit and might be one of the main causes for the high residual structures. The slant column density of $\mathrm{SO}_{2}$ was determined to $(1.6 \pm 0.1) \times 10^{19} \mathrm{molec} / \mathrm{cm}^{2}$.

In a second step, $\mathrm{SO}_{2}$ was evaluated in the long wave UV window between 360 and $390 \mathrm{~nm}$, where 5 weak absorption bands are located. As in the short wave UV evaluation besides $\mathrm{SO}_{2}$ and two $\mathrm{O}_{3}$ reference spectra taken from the same 
source and for the same temperatures as above, an $\mathrm{O}_{4}$ reference spectrum (Herman et al., 1999), $\mathrm{NO}_{2}$ at $246 \mathrm{~K}$ (Voigt et al., 2002), a Ring spectrum, and a Fraunhofer reference spectrum was included in the DOAS fit. Again, a 3rd order polynomial was applied to remove any broad-band structures, and a shift and 1st order squeeze were allowed for the measured spectra.

The DOAS evaluation results obtained in the long wave UV window for the same spectrum as evaluated before are shown in Fig. 1b. $\mathrm{SO}_{2}$ could also be clearly identified in this wavelength region, and in this case (3.2 \pm $0.4) \times 10^{19} \mathrm{molec} / \mathrm{cm}^{2}$ were found. The higher value obtained here is likely a result of a lower radiation dilution, as discussed in the section "Model Studies" below. Although the error of the SCD seems to be higher in the longer wavelength region, this is only because the given "Fit error" assumes a random residuum. As this is obviously not the case for the short wave UV retrieval, the "Fit error" is not a good measure of the measurement error (see Stutz and Platt, 1996). The amplitude of the residual structures $\left(9.7 \times 10^{-4} \mathrm{RMS}\right)$ is almost an order of magnitude lower than in the previous evaluation, and the features appear to be of random nature. The causes for the lower amplitude of the fit residual are:

- elimination of non-linear effects caused by high optical densities (see Frankenberg et al., 2005)

- reduced influence of spectrometer stray light in this well illuminated region of the detector

- the absence of a wavelength dependent air mass factor (see "Model Studies"), and

- the lower photon noise in the long wave UV window due to more incident radiation (see below).

The first point deals with the (apparent) saturation of $\mathrm{SO}_{2}$ absorption lines occurring at high optical densities. In such cases, a convolution of the $\mathrm{SO}_{2}$ absorption cross-section performed in optical density space does not quite match the optical density measured by the instrument (even if the light path of all measured photons is the same). The true measurement can be described by a convolution of the incident intensity with the spectrometer's instrument function. After the measurement, the logarithm is applied to obtain the optical density. For high optical densities, the logarithm and the convolution are not commutative, and the convolution must instead be performed in intensity space (Wenig et al., 2005).

The effect described by point 3 deals with the radiative transfer in and around the volcanic plume. $\mathrm{SO}_{2}$ absorption in the plume is sufficiently strong to significantly influence radiative transfer. The average light path in the plume is much shorter for wavelengths at which absorption is high (peaks of the $\mathrm{SO}_{2}$ absorption cross-section) than at wavelengths where the absorption is weaker (dips in the absorption cross-section). Therefore, the measured column density is a function of wavelength, a fact that is not taken into account in simple DOAS retrievals. However, the dependency of the measured column density of $\mathrm{SO}_{2}$ can be used to gain information on the radiative transfer in and around the plume (Kern et al., 2010), thus correcting the associated errors.

\subsection{Satellite measurement example}

As a second example we present the evaluation of satellite data from an overpass of the GOME-2 instrument after the eruption of the Kasatochi volcano (Aleutian Islands) on the 8 August 2008. The GOME-2 (Global Ozone Monitoring Experiment-2) on board of the MetOp satellite is the first of a series of three identical instruments. MetOp-A was launched into a sun synchronous polar orbit at $800 \mathrm{~km}$ altitude in October 2006. The satellite crosses the equator at 09:30 local time. GOME-2 is a 4 channel UV/Vis grating spectrometer observing the Earth's atmosphere in nadir viewing geometry (including up to $\pm 50^{\circ}$ difference to nadir). It measures both the radiance component of the light reflected by the Sun-illuminated Earth's atmosphere and the direct Sun light, covering the wavelength region of $240-790 \mathrm{~nm}$ at moderate spectral resolution of $0.2-0.4 \mathrm{~nm}$. With a pixel size of $80 \times 40 \mathrm{~km}(240 \times 40 \mathrm{~km}$ for the back scan $)$, GOME- 2 observes about 4 times smaller ground pixels than its predecessor GOME on ERS-2. By scanning the earth surface with a scan-width of $1920 \mathrm{~km}$, global coverage can be achieved within 1.5 days (EUMETSAT, 2005).

As in the first example, WinDoas V2.10 was used to derive the $\mathrm{SO}_{2} \mathrm{SCD}$ from the recorded spectra using a DOAS fit (spectral range 360-390 nm). For the Fraunhofer reference spectrum, the Sun Mean Reference Spectrum (SMR) of GOME-2 for that day was taken (containing no atmospheric absorptions) and again a "Ring" spectrum (Wagner et al., 2009) was calculated to compensate for the effect of Raman scattering.

For the short wave $\mathrm{UV} \mathrm{SO}_{2}$ evaluation of the satellite data, a slightly different fit range than for the ground-based measurements was chosen, covering the region between 312.1$324 \mathrm{~nm}$. Besides the $\mathrm{SO}_{2}$ reference spectrum (Bogumil et al., $2003,-293 \mathrm{~K})$, an $\mathrm{O}_{3}$ cross section $(221 \mathrm{~K}$, see Gür et al., 2005), the SMR, the Ring spectrum (calculated from the SMR) and an inverse SMR spectrum were included into the fitting process (the inverse SMR spectrum should compensate the effect of possible spectrograph stray-light). Since the atmospheric light paths within the selected fitting window change systematically with wavelength (e.g. Van Roozendael et al., 2006), not only the original ozone absorption cross section but also a second one (the original cross section scaled with a fourth order polynomial in wavelength) was included in the fitting algorithm (see also Puķite et al., 2010; Heue et al., 2010). It should be noted that, in principle, additional ozone absorption cross sections for other temperatures might be included into the fit. However, for the selected case study, no significant change of the retrieved $\mathrm{SO}_{2}$ results and the 

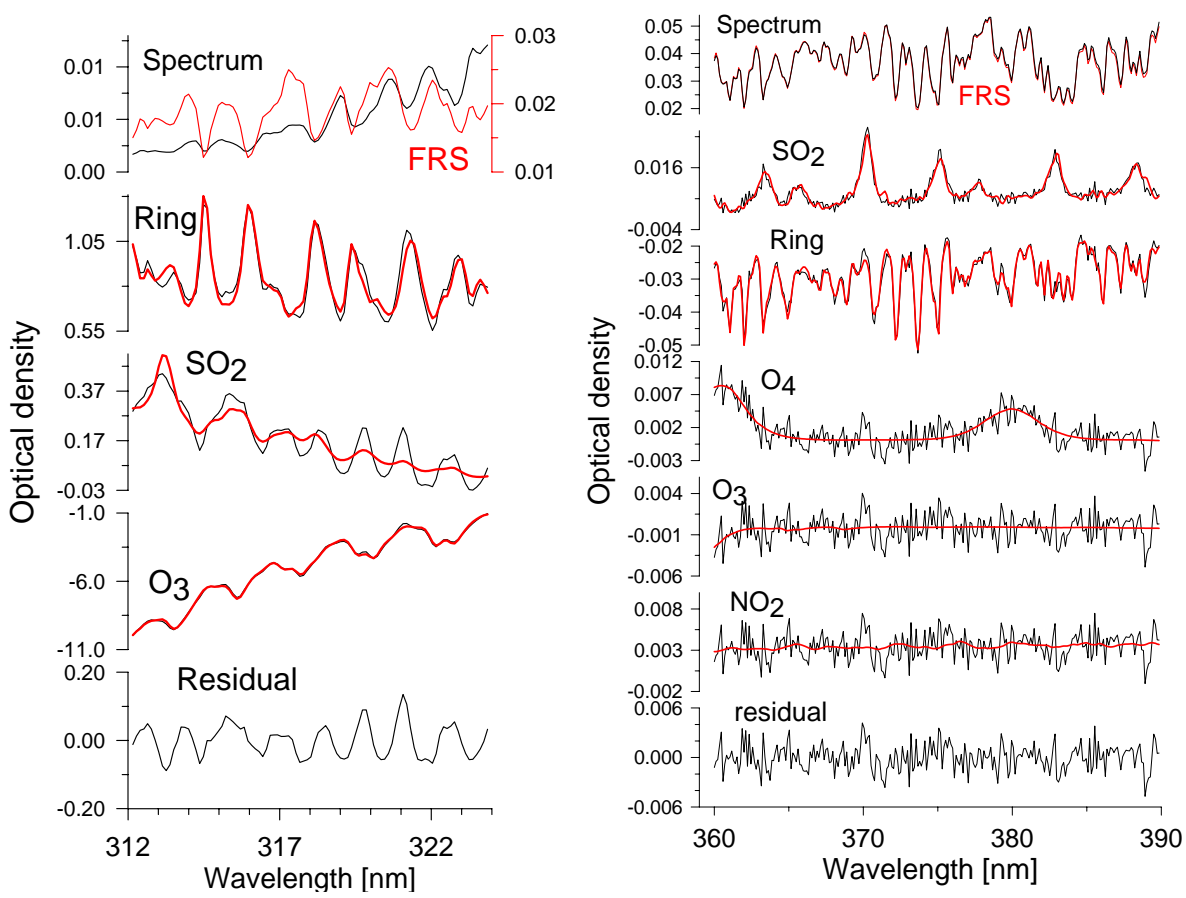

Fig. 2. Example of a DOAS $\mathrm{SO}_{2}$-Fit. Black lines: measured spectra, red lines: reference spectra, the atmospheric spectrum was taken by GOME-2 $\left(21: 25 \mathrm{UTC}\right.$, center pixel coordinates $\left.167.88^{\circ} \mathrm{W} 49.69^{\circ} \mathrm{N}\right)$ on the 8 August 2008 after the eruption of the Kasatochi volcano (a) evaluation in the short wave UV window $312.1-324 \mathrm{~nm}$ (b) evaluation in the long wave UV window 360-390 $\mathrm{nm}$.

magnitude of the residual were found, if additional temperatures were considered. A 5th order polynomial was applied to remove the broad-band structures and a slight wavelength shift was allowed for the measured spectra.

In Fig. 2a, the short wave UV fit results for the evaluation of one of the recorded spectra including the Kasatochi $\mathrm{SO}_{2}$ plume are shown. The $\mathrm{SO}_{2}$ signal can be clearly identified with a determined slant column density of $(2.2 \pm$ $0.3) \times 10^{18} \mathrm{molec} / \mathrm{cm}^{2}$. As in the ground-based example, the residual $\left(5 \times 10^{-2} \mathrm{RMS}\right)$ shows unexplained systematic structures. While for the selected case of very strong $\mathrm{SO}_{2} \mathrm{ab}-$ sorption the residual structures are probably mainly caused by the wavelength dependence of the $\mathrm{SO}_{2} \mathrm{AMF}$ (see also Fig. 7), part of the residual structures might be also related to imperfect correction of the Ring effect or the $\mathrm{O}_{3}$ absorption. Thus, the $\mathrm{SO}_{2}$ absorption structures can not be well described by simply including a single $\mathrm{SO}_{2}$ cross section in such cases.

The long wave $\mathrm{UV} \mathrm{SO}_{2}$ evaluation of the satellite data included, besides the above mentioned reference spectra for the short wave UV range, reference spectra for $\mathrm{O}_{4}$ (Greenblatt et al., 1990, $-298 \mathrm{~K}$ ) and $\mathrm{NO}_{2}$ (Vandaele, 1997, -294 K). Again a spectral shift for the measured spectra was allowed to correct for possibly occurring instrumental changes.

The results for the long wave UV evaluation can be seen in Fig. 2b, showing a significantly higher $\mathrm{SO}_{2}$ slant column density of $(4.7 \pm 0.1) \times 10^{19} \mathrm{molec} / \mathrm{cm}^{2}$ and are thus exceed- ing the value of the short wave UV evaluation by a factor of about 20. The now quite random looking residual structures are up to 50 times smaller than those obtained in when the short wave fit range $\left(2 \times 10^{-3} \mathrm{RMS}\right)$.

The spatial distribution of the $\mathrm{SO}_{2}$ plume on 8 August for the different evaluation ranges is presented in Fig. 3a-d. In Fig. 3a the plume can be clearly identified by the significantly enhanced $\mathrm{SO}_{2} \mathrm{SCD}$ values obtained in the short wave UV evaluation. For the long wave UV fit region, the plume can also be clearly identified in Fig. 3b (notice the SCD values are about a factor of 20 higher), however showing in principle the same shape. However, some interesting discrepancies remain. While the highest $\mathrm{SO}_{2}$ columns are measured in the north-east and south-west regions of the plume when using the short wave UV window, the maximum $\mathrm{SO}_{2}$ column is found in the south-east when using the long wave UV range (the maximum column densities are indicated by white stars inside Fig. 3a-b and d). As we show in the section "Model Studies", this is likely a result of a decreased sensitivity for high $\mathrm{SO}_{2}$ columns that occurs in short wave UV when $\mathrm{SO}_{2}$ absorption becomes so strong that radiation can no longer penetrate the volcanic plume (see Figs. 6 and 7). In order to illustrate the advantages of the long wave UV evaluation more clearly, the fit results for the previous used short wave region are shown in Fig. $3 c$ on the same scale as used for the long wave SCD results. Figure $3 \mathrm{~d}$ shows the corresponding VCD for the long wave UV fit region. 
(a)

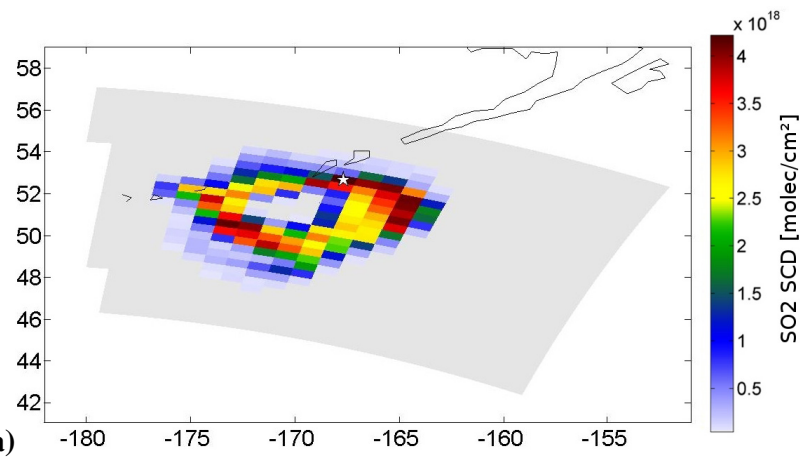

(c)

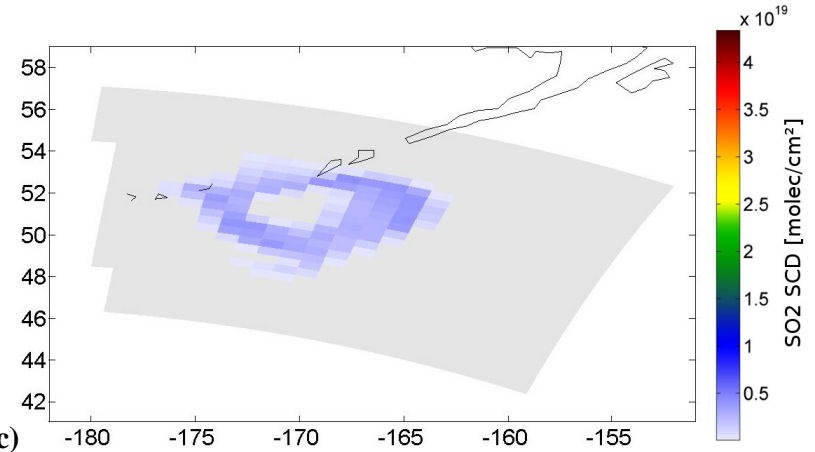

(b)

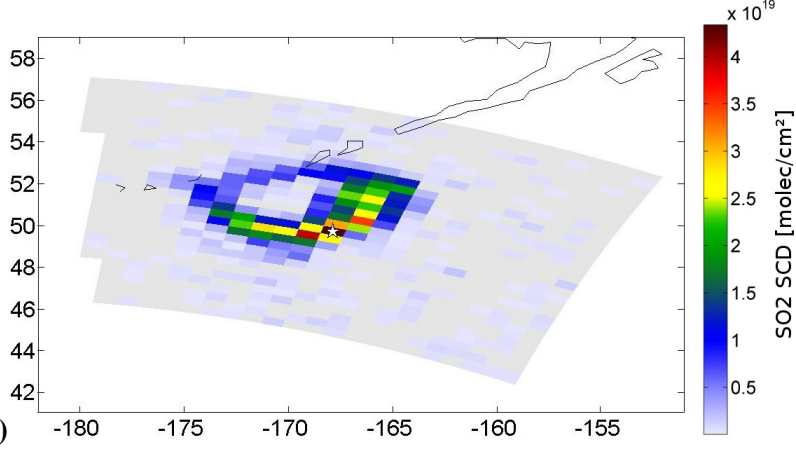

(d)

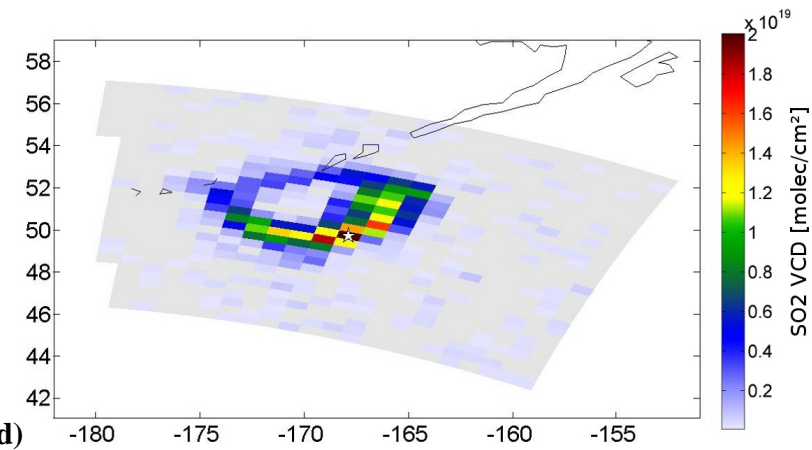

Fig. 3. $\mathrm{SO}_{2}$ plume after the Kasatochi eruption on 8 August 2008 recorded by GOME-2, The pixels with the maximum column densities are indicated by a white star. (a) evaluation in the short wave UV window $312.1-324 \mathrm{~nm}\left(\mathrm{max} \mathrm{SO} \mathrm{SCD}_{2} \approx 2.2 \pm 0.3 \times 10^{18} \mathrm{~mol} / \mathrm{cm}^{2}\right.$ (b) evaluation in the long wave UV window $360-390 \mathrm{~nm}\left(\max \mathrm{SO}_{2} \mathrm{SCD} \approx 4.7 \pm 0.1 \times 10^{19} \mathrm{~mol} / \mathrm{cm}^{2}\right)$ (c) evaluation in short wave UV window using the same color scale as shown in (b). (d) $\mathrm{SO}_{2} \mathrm{VCD}$ for the long wave UV window $360-390 \mathrm{~nm}\left(\mathrm{max} \mathrm{SO}_{2} \mathrm{VCD} \approx 1.87 \times\right.$ $\left.10^{19} \mathrm{~mol} / \mathrm{cm}^{2}\right)$.

The AMF calculation was done with the Monte-Carlo radiative transfer model McArtim, assuming the $\mathrm{SO}_{2}$ layer to be between 10 and $11 \mathrm{~km}$ (constant $\mathrm{SO}_{2}$ concentration of $1 \times 10^{14} \mathrm{molec} / \mathrm{cm}^{3}$ within this layer), including aerosols (aerosol optical depth: 3, asymmetry parameter: 0.68, single scattering albedo: 0.9). Additionally a cloud layer extending from 5 to $6 \mathrm{~km}$ (OD: 20, single scattering albedo: 1, asymmetry parameter: 0.85$)$ was included. Interestingly the VCD results are in general in good agreement with results from Richter et al. (2009), who derived VCDs from the short wavelength range, but accounted for the non-linearity effects.

\section{Discussion}

The absolute $\mathrm{SO}_{2}$ cross section (Fig. 4a) in the longer wavelength region is about three orders of magnitude smaller than in the commonly used shorter wavelength range. Unfortunately, the relative precision and accuracy of the $\mathrm{SO}_{2}$ absorption cross-section in the long wave UV is inferior compared to the short wave UV. Further studies are required to improve this, especially for low temperatures that occur at high latitudes.

Nevertheless, $\mathrm{SO}_{2}$ shows a characteristic high frequency structure in both regions, and the narrow band (differential) absorption features used for the DOAS evaluation are only about two orders of magnitude smaller in the long wave UV window (see Fig. 4b, c).

The disadvantage with regard to sensitivity and detection limit that this weaker system of absorption lines brings with it are largely compensated by a significantly better signal to noise ratio in the long wave UV region and a much lower residual (see above): The diffuse solar irradiance incident at the Earth's surface is about one order of magnitude higher in the long wave UV region than in the short wave UV window. As the noise of a DOAS measurement is typically dominated by photon noise (the magnitude of which is proportional to the square root of the measured intensity), measurements in the long wave UV window provide a 3 times better signal to noise ratio from photoelectron statistics for a given measurement integration time. Another factor of two is gained by using a wider wavelength region for the long wave UV wavelength evaluation, which adds another factor of 1.4 to the signal to noise ratio. Moreover, the quantum efficiency of typical compact spectrometer detectors is better in the long wave UV and, due to reduced distortion of the band shape (see discussion above, the amplitude of the residuum is lower in the long wave UV range. 

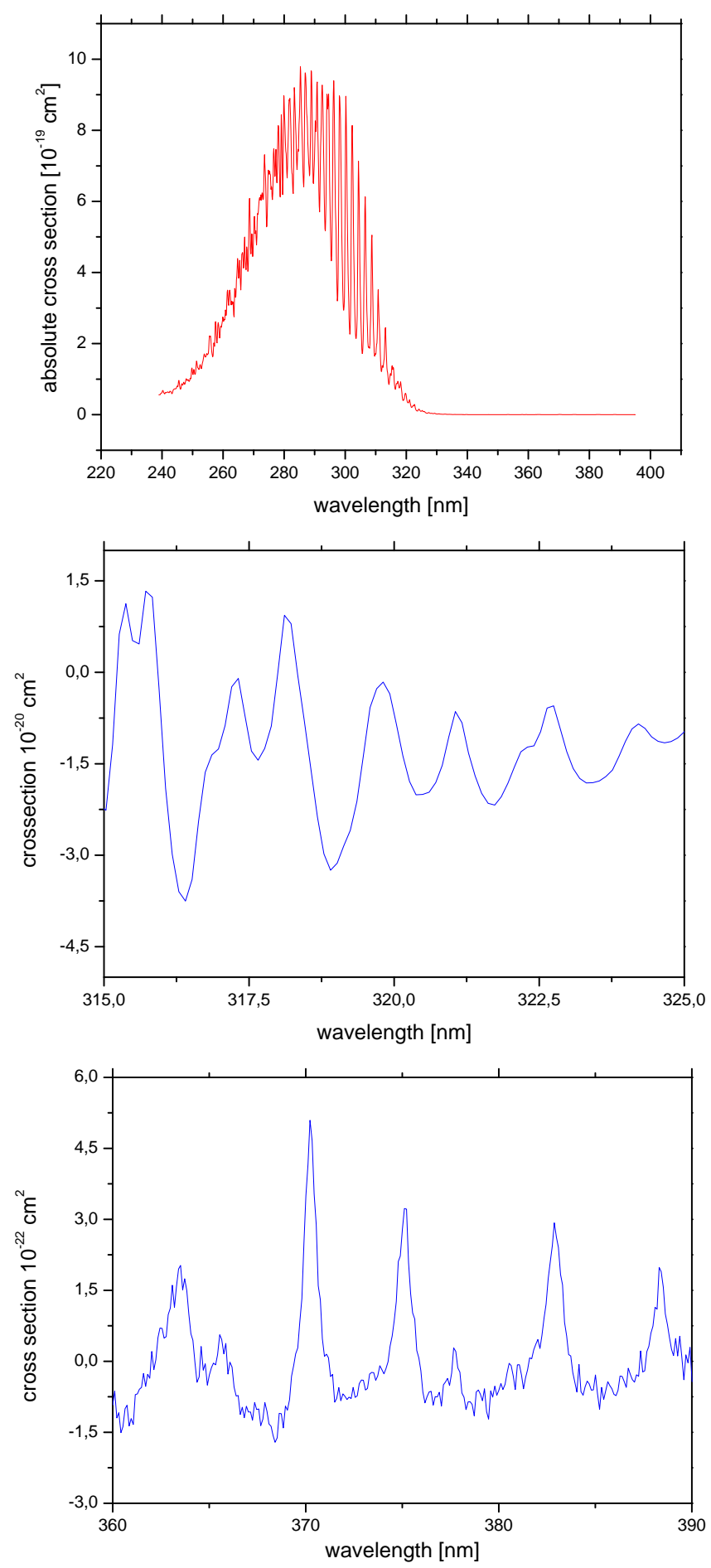

Fig. 4. $\mathrm{SO}_{2}$ cross section for $273 \mathrm{~K}$ from Bogumil et al. (2003) (a) absolute cross section, (b) Differential cross section high pass filtered for the wavelength range $315-325 \mathrm{~nm}$ (c) Differential cross section high pass filtered for the wavelength range 360 $390 \mathrm{~nm}$. The differential absorption cross sections are $\approx 4.5 \times$ $10^{-20} \mathrm{~cm}^{2} /$ molec and $6 \times 10^{-22} \mathrm{~cm}^{2} /$ molec for the short wave UV and long wave UV regions, respectively.
In summary, the overall loss in sensitivity when switching to the longer wavelength window (long wave UV) can be estimated at about an order of magnitude. While this may seem high, a considerable fraction of volcanic $\mathrm{SO}_{2}$ emissions measurements are conducted under conditions in which the lower sensitivity is not an issue, and the potentially improved accuracy of evaluations in the long wave UV region is arguably more important.

\section{Model studies}

\subsection{Ground based geometry}

A model study was conducted to investigate the influence of radiation transport on ground-based remote sensing measurements performed in the long wave UV wavelength region around $375 \mathrm{~nm}$ in comparison to the standard short wave UV range around $320 \mathrm{~nm}$. In this study, the backward Monte-Carlo radiative transfer model McArtim (Deutschmann, 2008) was used to simulate the propagation of radiation between the sun and a simulated instrument located on the ground at various distances from the centre of a volcanic plume.

The geometry of the model run corresponds to the measurements at Mt. Etna on 10 June 2008. A volcanic plume with a $450 \mathrm{~m}$ diameter circular cross section was simulated $250 \mathrm{~m}$ above the ground, the DOAS instrument, was located $350 \mathrm{~m}$ from the plume centre. While the plume contained $\mathrm{SO}_{2}$ and aerosols, aerosol-free ambient atmospheres was assumed, an assumption that is justified by the observed clear sky conditions above and around the plume on the date of the measurement (see Sect. 3.1). The model atmosphere exhibited a typical stratospheric ozone profile to account for the influence of ozone on radiative transfer in the upper atmosphere.

Using the radiative transfer model as a forward model for the measurement results, an iterative problem inversion was performed in which the $\mathrm{SO}_{2}$ concentration and the aerosol extinction coefficient inside the simulated plume were varied until the modelled spectral intensity, when divided by the modelled spectral intensity in a viewing direction outside the plume and after applying the logarithm, matched the measured optical density. The details of this procedure are subject of a separate manuscript in preparation.

The best fit, both, to the measured spectrum between 306 and $324 \mathrm{~nm}$ as well as to the measured column density at $375 \mathrm{~nm}$ was achieved for a plume $\mathrm{SO}_{2}$ concentration of $4.1 \times 10^{11} \mathrm{molec} / \mathrm{cm}^{3}$, which corresponds to a straight column of $1.85 \times 10^{19} \mathrm{molec} / \mathrm{cm}^{2}$ and an aerosol extinction coefficient of approximately $80 \mathrm{~km}^{-1}$. Therefore, these values are assumed to be the best estimate for the true conditions inside the volcanic plume.

However, a standard DOAS evaluation will not necessarily give these values. As described by Kern et al. (2010), a naive 
DOAS approach can yield considerable errors, especially if the measurements are conducted at a large distance from the plume or if the plume contains a high aerosol load. As an aerosol extinction coefficient of $80 \mathrm{~km}^{-1}$ corresponds to an approximate visibility of only $50 \mathrm{~m}$; a value that is not unrealistic considering the high opacity of the plume caused by condensation of water vapour, considerable errors can be expected in standard DOAS retrievals in this example as well. One indication of this fact is the factor of 2 difference between the result of the evaluation in the short wave UV window compared to that of the long wave UV range.

The question which of the two evaluation ranges generally gives the better results cannot be answered without taking into account the distance to the plume. In the example measurement at Mt. Etna, the instrument was located next to the active crater and therefore the distance to the plume was exceptionally small (assumed to be $350 \mathrm{~m}$ in the model run). In this case, the short wave UV seems to give the better result, as the retrieved CD of $1.6 \times 10^{19} \mathrm{molec} / \mathrm{cm}^{2}$ is closer to the radiative transfer model inversion result of $1.85 \times 10^{19} \mathrm{molec} / \mathrm{cm}^{2}$ than the $3.2 \times 10^{19} \mathrm{molec} / \mathrm{cm}^{2}$ obtained in the long wave UV range. However, this situation changes rapidly if the measurements are conducted farther away from the plume. Figure 5 shows the simulated air mass factor (AMF) for a measurement of the above described plume as a function of distance between instrument and plume. Both 320 and $375 \mathrm{~nm}$ are shown, it should however be noted that the simulations performed at $320 \mathrm{~nm}$ are not necessarily indicative of the radiative transfer in the entire region between 300 and $330 \mathrm{~nm}$, as the AMF is strongly dependent on wavelength in this region (see Kern et al., 2010).

The first data points shown in Fig. 5 are the results of model runs conducted for the exact geometry used for the radiative transfer inversion, i.e. the distance to the plume center was $350 \mathrm{~m}$. In this geometry, the long wave UV range yields an AMF of almost 1.75, thus indicating a light path extension by $75 \%$ inside the plume due to multiple scattering. At $320 \mathrm{~nm}$, the light path is also enhanced by multiple scattering, but the strong $\mathrm{SO}_{2}$ absorption leads to an AMF of about 0.75. For this geometry, a standard DOAS retrieval in the short wave UV range is therefore expected to slightly underestimate the true straight $\mathrm{CD}$, while a retrieval in the long wave UV will overestimate the CD by $75 \%$.

However, as the instrument is moved farther from the plume in the simulation, the AMF rapidly decreases in both cases, an effect that is caused by radiation entering the line of sight between plume and instrument, thus diluting the signal. The AMF at $320 \mathrm{~nm}$ drops below 0.5 at $750 \mathrm{~m}$, and continues to decrease as the distance is increased. At $375 \mathrm{~nm}$, the situation is much better. Here, the AMF drops to approximately unity at $1 \mathrm{~km}$ distance and then declines more slowly, thus staying close to one for a large range of distances from the plume.

The results of this model study show that the novel evaluation range is better suited for DOAS measurements of $\mathrm{SO}_{2}$

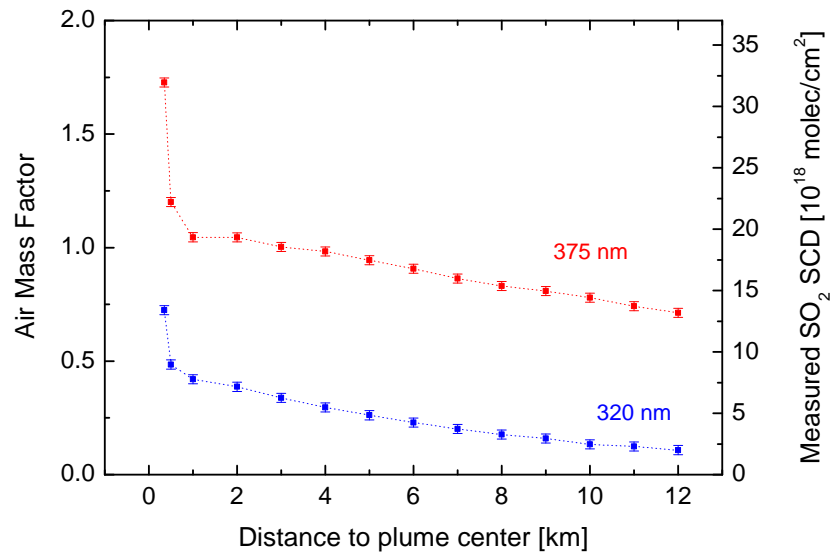

Fig. 5. Simulated air mass factors (AMF) for remote sensing measurements of a volcanic plume with high aerosol load performed at 320 (shown in blue) and $375 \mathrm{~nm}$ (shown in red). The distance between the volcanic plume and the remote sensing instrument was varied between 1 and $12 \mathrm{~km}$.

in volcanic plumes with high $\mathrm{SO}_{2}$ and aerosol loads when the instruments are located at distances larger than approximately $1 \mathrm{~km}$ from the plume. While the exact AMF of such measurements will depend on the conditions inside the plume as well as the aerosol load in the ambient atmosphere, the described example shows that the dilution effect is considerably less prominent for the long wave UV evaluation region than for wavelengths around $315 \mathrm{~nm}$.

To obtain accurate results, it is necessary to retrieve the effective radiation path length in the volcanic plume, as the measured column density can be highly dependent on wavelength. Only then can the true straight column density (and therefore the average concentration) be accurately assessed. It was recently shown that the wavelength-dependent air mass factor can be retrieved from the measured $\mathrm{SO}_{2}$ optical densities between 300 and $325 \mathrm{~nm}$ (Kern et al., 2010). Furthermore, the algorithm described by Kern et al. (2010) could be expanded to include wavelengths around $380 \mathrm{~nm}$, thus increasing the information content in the model inversion.

\subsection{Satellite geometry}

The GOME-2 observations of the Kasatochi eruption were also simulated using the full spherical Monte Carlo radiative transfer model McArtim (Deutschmann, 2008). To simplify the simulations, fixed values for the viewing geometry were assumed (SZA: $50^{\circ}$, viewing angle: $-90^{\circ}$ ). The layer of enhanced $\mathrm{SO}_{2}$ concentrations was assumed to be between 10 and $11 \mathrm{~km}$ (constant $\mathrm{SO}_{2}$ concentration within this layer). Below the $\mathrm{SO}_{2}$ layer, a cloud layer extending from 5 to $6 \mathrm{~km}$ (OD: 20, single scattering albedo: 1 , asymmetry parameter: 0.85 ) was included in the simulations. Two basic model runs were performed: the first one without aerosols and the second including aerosols within the $\mathrm{SO}_{2}$ 


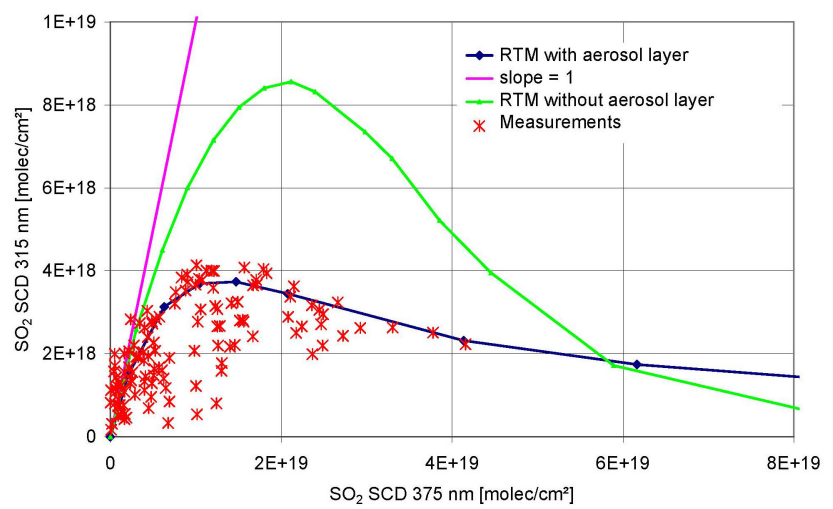

Fig. 6. Simulated $\mathrm{SO}_{2} \mathrm{SCDs}$ for $315 \mathrm{~nm}$ versus $\mathrm{SO}_{2} \mathrm{SCDs}$ at $375 \mathrm{~nm}$ for satellite remote sensing of the Kasatochi $\mathrm{SO}_{2}$ plume on 8 August 2008 for two cases: without aerosols or with aerosol inside the plume (optical depth of 3). In addition to the modelled $\mathrm{SO}_{2}$ SCDs also the GOME-2 measurements are included in the figure. Only if aerosols are present in the plume, simulations and measurements are in agreement.

layer (aerosol optical depth: 3, asymmetry parameter: 0.68 , single scattering albedo: 0.9). For both runs the $\mathrm{SO}_{2}$ concentration was varied from zero to $5 \times 10^{14} \mathrm{molec} / \mathrm{cm}^{3}$, and the corresponding $\mathrm{SO}_{2} \mathrm{SCDs}$ were calculated for both of the regarded wavelengths ( 315 and $375 \mathrm{~nm}$ ).

The results are presented in Fig. 6, where the modelled $\mathrm{SO}_{2} \mathrm{SCDs}$ for $315 \mathrm{~nm}$ are plotted versus those at $375 \mathrm{~nm}$. In addition to the modelled $\mathrm{SO}_{2} \mathrm{SCDs}$ also the measurements for 8 August 2008 are included in the figure. In both model runs a linear relationship between the $\mathrm{SO}_{2} \mathrm{SCDs}$ for both wavelengths is only found for rather small $\mathrm{SO}_{2}$ concentrations (about $<1 \times 10^{13} \mathrm{molec} / \mathrm{cm}^{3}$, corresponding to about $2.5 \times 10^{18} \mathrm{molec} / \mathrm{cm}^{2}$ ). For higher concentrations, the $\mathrm{SO}_{2}$ SCDs for $315 \mathrm{~nm}$ increase much slower compared to those for $375 \mathrm{~nm}$, and eventually they even decrease if the $\mathrm{SO}_{2}$ concentration is further increased. This is a result of the very strong light absorption caused by $\mathrm{SO}_{2}$ inside the volcanic plume. If aerosols are present, this effect is less pronounced (and for very high $\mathrm{SO}_{2}$ concentrations even higher $\mathrm{SO}_{2} \mathrm{SCDs}$ for $315 \mathrm{~nm}$ are found compared to the non-aerosol case), because more light is scattered back by the aerosol particles to the satellite instrument from the layer of enhanced $\mathrm{SO}_{2}$. The comparison with the measured $\mathrm{SO}_{2} \mathrm{SCDs}$ clearly indicates that it is not possible to describe the satellite observations from 8 August 2008 without aerosols present in the volcanic plume. Good agreement for the upper bound of measured $\mathrm{SO}_{2} \mathrm{SCDs}$ for $315 \mathrm{~nm}$ is found for an assumed aerosol optical depth of about 3 . The scatter of the measured data indicates that the aerosol load was different (and mostly higher than 3) in different parts of the observed plume.

Additionally Fig. 7 shows the strong dependency of the AMF on the $\mathrm{SO}_{2} \mathrm{VCD}$ for the different wavelengths. While the AMF for the short wave UV range rapidly decrease for

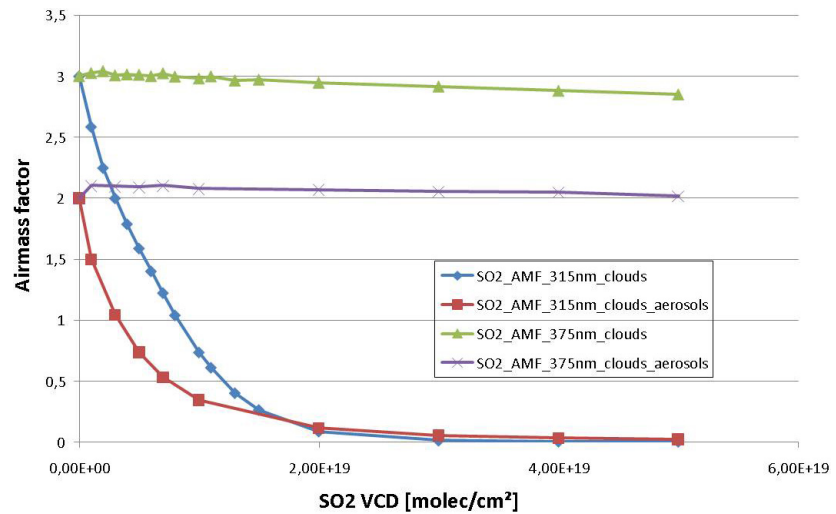

Fig. 7. AMF dependency on the $\mathrm{SO}_{2} \mathrm{VCD}$, wavelength and aerosols. While the AMF for the short wave UV range rapidly decrease for large $\mathrm{SO}_{2} \mathrm{VCDs}$, it almost remains constant for the long wave UV range. In the presence of aerosols, the reduced sensitivity is less pronounced for very high $\mathrm{SO}_{2}$ loads $\left(>2 \times 10^{19} \mathrm{~mol} / \mathrm{cm}^{2}\right)$, because more light is scattered back by the aerosol particles to the satellite instrument from the layer of enhanced $\mathrm{SO}_{2}$.

large $\mathrm{SO}_{2}$ VCDs, it almost remains constant for the long wave UV range.

\section{Conclusions}

An alternative evaluation range for the DOAS retrieval of $\mathrm{SO}_{2}$ was proposed. It was shown that using the long wave UV window of 360-390 nm has a number of advantages in situations in which high $\mathrm{SO}_{2}$ column densities are encountered. In particular, problems with non-linearity in the DOAS evaluation, stray light in the spectrometer, and signal dilution by scattering could be avoided or at least significantly reduced.

Although the absolute $\mathrm{SO}_{2}$ absorption cross section in the long wave UV range is about three orders of magnitude smaller than around $320 \mathrm{~nm}$, the high frequency (differential) absorption features are only about two orders of magnitude smaller. Because the intensity of incident solar radiation on the ground is about an order of magnitude higher in the long wave UV region, the smaller sensitivity towards $\mathrm{SO}_{2}$ can in part be compensated by a lower photon noise level (about a factor of 4.2). However, since the quality of volcanic $\mathrm{SO}_{2}$ measurements using the DOAS technique are rarely limited by instrument sensitivity but rather by retrieval accuracy, the suggested long wave UV evaluation region can be advantageous in many situations.

A model study conducted to investigate radiative transfer showed that DOAS evaluations in the long wave UV region will give more accurate results in situations where high plume $\mathrm{SO}_{2}$ loads and long distances between the instrument and the volcanic plume prevail. This is especially true for satellite measurements. The novel evaluation window is less 
susceptible to radiation dilution and wavelength dependent air mass factors (and column densities). In the ground-based measurement described above, the $\mathrm{SO}_{2}$ column density was overestimated by the retrieval in the long wave UV region, but this effect was ascribed to the close proximity of the volcanic plume. In typical measurement geometries in which the plume is located some kilometres from the instrument, the short wave UV region will usually yield AMFs significantly below unity, while the novel evaluation range yields AMFs much closer to one.

The results from the satellite data evaluation example using GOME-2 data emphasizes the advantages of the long wave UV fit range in cases of high $\mathrm{SO}_{2}$ column densities. In particular, the radiative transfer study showed that evaluation in the short wave UV region can lead to a strong underestimation of the retrieved $\mathrm{SO}_{2}$ column densities due to the strongly reduced probability that the observed scattered light has penetrated the plume. Interestingly, for cases of very strong $\mathrm{SO}_{2}$ absorption, the presence of aerosols within the plume leads to a slight increase of the sensitivity. By assuming an aerosol optical depth of 3 in the radiative transfer simulations the model results are in good agreement with the upper bound of measured $\mathrm{SO}_{2} \mathrm{SCDs}$ for the short wave UV region.

The most accurate DOAS $\mathrm{SO}_{2}$ measurements in volcanic plumes can be obtained by fully taking into account the radiative transfer in each performed measurement. Modern radiative transfer models can be used to invert the measurement conditions (including $\mathrm{SO}_{2}$ concentration and aerosol extinction coefficient). However, the complexity of this procedure greatly exceeds the current standard DOAS retrievals, computer processing time becomes an issue, and certain scenarios can lead to high degrees of uncertainty in the inversion, as will be discussed in an upcoming manuscript. One observation can, however, be made already: Adding the information obtained in the long wave UV spectral region to constrain the radiative transfer calculation in situations where this is possible will greatly improve the retrieval accuracy.

Finally, the implications of this study go beyond the measurement of $\mathrm{SO}_{2}$ in volcanic plumes alone. While somewhat less sensitive, the novel evaluation range can also be applied to data evaluations of industrial plume measurements or urban pollution in general. The long wave UV range could for example also be applied to satellite data over highly polluted regions like China.

In summary, the proposed long wave UV retrieval range not only represents an additional, independent retrieval technique that can be used to validate measurements evaluated in the short wave UV, it also gives additional information which, if interpreted correctly, can further increase our understanding of radiative transfer in and around volcanic plumes.

Edited by: D. Loyola

\section{References}

Bobrowski, N., Hönninger, G., Galle, B., and Platt, U.:Detection of Bromine Monoxide in a Volcanic Plume, Nature, 423, 273-276, 2003.

Bobrowski, N. and Platt, $\mathrm{U}$.: $\mathrm{SO}_{2} / \mathrm{BrO}$ ratios studied in five volcanic plumes, J. Volcanol. Geothe. Res., 166, 147-160, 2007.

Bobrowski, N., von Glasow, R., Aiuppa, A., Inguaggiato, S., Louban, I., Ibrahim, O. W., and Platt, U.: Reactive halogen chemistry in volcanic plumes, J. Geophys. Res., 112, D06311, doi:10.1029/2006JD007206, 2007.

Bogumil, K., Orphal, J., Homann, T., Voigt, S., Spietz, P., Fleischmann, O. P., Vogel, A., Hartmann, M., Bovensmann, H., Frerik, J., and Burrows, J. P.: Measurements of Molecular Absorption Spectra with the SCIAMACHY PreFlight Model: Instrument Characterization and Reference Data for Atmospheric Remote-Sensing in the 230-2380 nm Region, J. Photoch. Photobio. A., 157, 67-184, 2003.

Bussemer, M.: Der Ring-Effekt: Ursachen und Einfluß auf die spektroskopische Messung stratosphärischer Spurenstoffe, Diploma Thesis in Physics, University of Heidelberg, 1993.

Deutschmann, T.: Atmospheric radiative transfer modelling with Monte Carlo methods, Diploma Thesis in Physics, University of Heidelberg, 2008.

Eisinger, M. and Burrows, J. P.: Tropospheric Sulfur Dioxide observed by the ERS-2 GOME Instrument, Geophys. Res. Lett., 25, 4177-4180, 1998.

Eskes, H. J. and Boersma, K. F.: Averaging kernels for DOAS totalcolumn satellite retrievals, Atmos. Chem. Phys., 3, 1285-1291, doi:10.5194/acp-3-1285-2003, 2003.

EUMETSAT: GOME-2 Products Guide, http://oiswww.eumetsat. org/WEBOPS/eps-pg/GOME-2/GOME2-PG-0TOC.htm, 2005.

Fayt, C. and Roozendael, M. V.: WinDOAS 2.1. Software User Manuel, 2001.

Frankenberg, C., Platt, U., and Wagner, T.: Iterative maximum a posteriori (IMAP)-DOAS for retrieval of strongly absorbing trace gases: Model studies for $\mathrm{CH}_{4}$ and $\mathrm{CO}_{2}$ retrieval from near infrared spectra of SCIAMACHY onboard ENVISAT, Atmos. Chem. Phys., 5, 9-22, doi:10.5194/acp-5-9-2005, 2005.

Galle, B., Oppenheimer, C., Geyer, A., McGonigle, A., Edmonds, M., and Horrocks, L.: A miniaturised ultraviolet spectrometer for remote sensing of $\mathrm{SO}_{2}$ Fluxes: A new tool for volcano surveillance, J. Volcanol. Geothe. Res., 119, 214-254, 2003.

Galle, B., Johansson, M., Rivera, C., Zhang, Y., Kihlman, M., Kern, C., Lehmann, T., Platt, U., Arellano, S., and Hidalgo, S.: NOVAC - A global network for volcano gas monitoring, network layout and instrument description, J. Geophys. Res., doi: 10.1029/2009JD011823, in press, 2010.

Greenblatt, G. D., Orlando, J. J., Burkholder, J. B., and Ravishankara, A. R.: Absorption Measurements of Oxygen between 330 and $1140 \mathrm{~nm}$, J. Geophys. Res., 95(D11), 18577-18582, 1990.

Gür, B., Spietz, P., Orphal, J., and Burrows, J.: Absorption Spectra Measurements with the GOME-2 FMs using the IUP/IFEUB's Calibration Apparatus for Trace Gas Absorption Spectroscopy CATGAS, Final Report, IUP University of Bremen, October 2005.

Hermans, C., Vandaele, A. C., Carleer, M., Fally, S., Colin, R., Jenouvrier, A., Coquart, B., and Merienne, M. F.: Absorption Cross-Sections of Atmospheric Constituents: $\mathrm{NO}_{2}, \mathrm{O}_{2}$, and 
$\mathrm{H}_{2} \mathrm{O}$, Environ. Sci. Pollut. R., 6(3), 151-158, 1999.

Heue, K.-P., Brenninkmeijer, C. A. M., Wagner, T., Mies, K., Dix, B., Frieß, U., Martinsson, B. G., Slemr, F., and van Velthoven, P. F. J.: Observations of the 2008 Kasatochi volcanic $\mathrm{SO}_{2}$ plume by CARIBIC aircraft DOAS and the GOME-2 satellite, Atmos. Chem. Phys., 10, 4699-4713, doi:10.5194/acp-10-4699-2010, 2010.

Hönninger, G., von Friedeburg, C., and Platt, U.: Multi axis differential optical absorption spectroscopy (MAX-DOAS), Atmos. Chem. Phys., 4, 231-254, doi:10.5194/acp-4-231-2004, 2004a.

Hönninger, G., Bobrowski, N., Palenque, E., Torrez, R., and Platt, U.: Reactive bromine and sulfur emissions at Salar de Uyuni, Bolivia, Geophys. Res. Lett., 31, L04101, doi:10.1029/2003GL018818, 2004b.

Horton, K. A., Williams-Jones, G., Garbeil, H., Elias, T., Sutton, A. J., Mouginis-Mark, P., Porter, J. N., and Clegg, S.: Real-time measurement of volcanic $\mathrm{SO}_{2}$ emissions: validation of a new $\mathrm{UV}$ correlation spectrometer (FLYSPEC), Bull. Volcanol., 68, 323327, doi:10.1007/s00445-005-3880014-9, 2006.

Kern C.: Spectroscopic measurements of volcanic gas emissions in the ultra-violet wavelength region, Ph.D. thesis, University of Heidelberg, 318 pp., http://www.ub.uni-heidelberg.de/archiv/ 9574, Heidelberg, 2009.

Kern, C., Deutschmann, T., Vogel, L., Wöhrbach, M., Wagner, T., and Platt, U.: Radiative transfer corrections for accurate spectroscopic measurements of volcanic gas emissions, Bull. Volcanol., 72, 233-247, doi:10.1007/s00445-009-0313-7, 2010

Khokhar, M. F., Frankenberg, C., Beirle, S., Kühl, S., Van Roozendael, M., Richter, A., Platt, U., and Wagner, T.: Satellite Observations of Atmospheric $\mathrm{SO}_{2}$ from Volcanic Eruptions during the Time Period of 1996 to 2002, J. Adv. Space Res., 36(5), 879887, doi:10.1016/j.asr.2005.04.114, 2005.

Kraus, S.: The DOASIS software, Chapter Presentation at the 1st international DOAS Workshop, Heidelberg, 2001.

Kromminga, H., Orphal, J., Spietz, P., Voigt, S., and Burrows, J. P.: New measurements of $\mathrm{OClO}$ absorption cross sections in the 325-435 $\mathrm{nm}$ and their temperature dependence between 213 293 K, J. Photoch. Photobiol. A., 157, 149-160, 2003.

Krotkov, N. A., Carn, S. A., Krueger, A. J., Bhartia, P. K., and Yang, $\mathrm{K}$.: Band residual difference algorithm for retrieval of $\mathrm{SO}_{2}$ from the Aura Ozone Monitoring Instrument (OMI), IEEE T. Geosci. Remote, AURA Special Issue, 44(5), 1259-1266, 2006.

Krueger, A. J.: Sighting of El Chichon sulfur dioxide clouds with the Nimbus 7 Total Ozone Mapping Spectrometer, Science, 220, 1377-1378, 1983.

Krueger, A. J., Walter, L. S., Bhartia, P. K., Schnetzler, C. C., Krotkov, N. A., Sprod, I., and Bluth, G. J. S.: Volcanic sulfur dioxide measurements from the Total Ozone Mapping Spectrometer (TOMS)Instruments, J. Geophys. Res., 100(D7), 1405714076, 1995.

Krueger, A., Krotkov, N., and Carn, S.: El Chichon: The genesis of volcanic sulfur dioxide monitoring from space, J. Volcanol. Geothe. Res., 175(4), 408-414, doi:10.1016/j.jvolgeores.2008.02.026, 2008.

Kurucz, R. L., Furenlid, I., Brault, J., and Testerman, L.: Solar flux atlas from 296 to $1300 \mathrm{~nm}$, National Solar Observatory, Sunspot, New Mexico, 240 pp., 1984.

Lee, C., Richter, A., Weber, M., and Burrows, J. P.: $\mathrm{SO}_{2}$ Retrieval from SCIAMACHY using the Weighting Function DOAS (WF-
DOAS) technique: comparison with Standard DOAS retrieval, Atmos. Chem. Phys., 8, 6137-6145, doi:10.5194/acp-8-61372008, 2008.

McGonigle, A. J .S.: Measurement of volcanic $\mathrm{SO}_{2}$ fluxes with differential optical absorption spectroscopy, J. Volcanol. Geothe. Res. 162, 111-122, doi:10.1016/j.jvolgeores.2007.02.001, 2007.

Millan, M., Townsend, S., and Davies, J.: Study of the Barringer refractor plate correlation spectrometer as a remote sensing instrument, Utias rpt. 146, M.Sc. thesis, University of Toronto, Toronto, Ontario, Canada, 1969.

Millán, M. M.: Remote sensing of air pollutants: A study of some atmospheric scattering effects, Atmos. Environ. 14, 1241-1253, 1980.

Mori, T., Mori, T., Kazahaya, K., Ohwada, M., Hirabayashi, J., and Yoshikawa, S.: Effect of UV scattering on $\mathrm{SO}_{2}$ emission rate measurements, Geophys. Res. Lett., 33, L17315, doi: 10.1029/2006GL026285, 2006.

Noxon, J. F.: Nitrogen dioxide in the stratosphere and troposphere measured by ground-based absorption spectroscopy, Science, 189, 547-549, 1975.

Palmer, P. I., Jacob, D. J., Chance, K., Martin, R. V., Spurr, R. J . D., Kurosu, T. P., Bey, I., Yantosca, R., Fiore, A., and Li, Q.: Air mass factor formulation for spectroscopic measurements from satellites: Application to formaldehyde retrievals from the Global Ozone Monitoring Experiment, J. Geophys. Res., 106, 14539-14550, 2001.

Perner, D., Ehhalt, D. H., Pätz, H. W., Platt, U., Roth, E. P., and Volz, A.: OH Radicals in the lower Troposphere, Geophys. Res. Lett., 3, 466-468, 1976.

Platt, U., Perner, D., and Pätz, H.: Simultaneous measurements of atmospheric $\mathrm{CH}_{2} \mathrm{O}, \mathrm{O}_{3}$ and $\mathrm{NO}_{2}$ by differential optical absorption, J. Geophys. Res. 84, 6329-6335, 1979.

Platt, U. and Stutz, J.: Differential Optical Absorption spectroscopy, Principles and Applications, Springer, XV, 597 pp., 272 illus., 29 in color, (Physics of Earth and Space Environments), ISBN 9783-540-21193-8, 2008.

Puksīe, J., Kühl, S., Deutschmann, T., Platt, U., and Wagner, T.: Extending differential optical absorption spectroscopy for limb measurements in the UV, Atmos. Meas. Tech., 3, 631-653, doi:10.5194/amt-3-631-2010, 2010.

Richter, A. and Burrows, J. P.: Tropospheric $\mathrm{NO}_{2}$ from GOME Measurements, Adv. Space Res., 29(11), 1673-1683, 2002.

Richter, A., Wittrock, F., Schönhardt, A., and Burrows, J. P.: Quantifying volcanic $\mathrm{SO}_{2}$ emissions using GOME-2 measurements, poster at the EGU2009-7679, AS3.15, XY247 (http://www.iup. uni-bremen.de/doas/posters/egu_2009_richter.pdf), 2009.

Solomon, S., Schmeltekopf, A. L., Sanders, R. W.: On the interpretation of zenith sky absorption measurements, J. Geophys. Res., 92, 8311-8319, 1987.

Vandaele, A. C., Hermans, C., Simon, P. C. , Carleer, M., Colin, R., Fally, A., Mérienne, M. F., Jenouvrier, A., and Coquart, B.: Measurements of the $\mathrm{NO}_{2}$ absorption cross-section from $42000 \mathrm{~cm}^{-1}$ to $10000 \mathrm{~cm}^{-1}(238-1000 \mathrm{~nm})$ at 220 and $294 \mathrm{~K}$, J. Quant. Spectrosc. Ra., 59, 171-184, 1997.

Van Roozendael, M., Loyola, D., Spurr, R., Balis, D., Lambert, J. C., Livschitz, Y., Valks, P., Ruppert, T., Kenter, P., Fayt, C., and Zehner, C.: Ten years of GOME/ERS-2 total ozone data - The new GOME data processor (GDP) version 4:1, Algorithm description, J. Geophys. Res., 111, D14311, 
doi:10.1029/2005JD006375, 2006.

Van Roozendael, M., Pinardi, G., Hermans, C., Fayt, C., and Merlaud, A.: MiniDOAS calibration issues, 2nd NOVAC retrieval workshop, Gothenburg, Sweden, 19 December 2006.

Voigt, S., Orphal, J., Bogumil, K., and Burrows, J. P.: The temperature dependence (203-293 K) of the absorption cross sections of $\mathrm{O}_{3}$ in the $230-850 \mathrm{~nm}$ region measured by Fourier-transform spectroscopy, J. Photoch. Photobiol. A., 143, 1-9, 2001.

Voigt, S., Orphal, J., and Burrows, J. P.: The temperature and pressure dependence of the absorption cross sections of $\mathrm{NO}_{2}$ in the $250-800 \mathrm{~nm}$ region measured by Fourier-transform spectroscopy, J. Photochem. Photobiol. A., 143, 1-9, 2002.

Volkamer, R., Etzkorn, T., Geyer, A., and Platt, U.: Correction of the oxygen interference with UV spectroscopic (DOAS) measurements of monocyclic aromatic hydrocarbons in the atmosphere, Atmos. Environ., 32, 3731-3747, 1998.

Wagner, T., Burrows, J. P., Deutschmann, T., Dix, B., von Friedeburg, C., Frieß, U., Hendrick, F., Heue, K.-P., Irie, H., Iwabuchi, H., Kanaya, Y., Keller, J., McLinden, C. A., Oetjen, H., Palazzi, E., Petritoli, A., Platt, U., Postylyakov, O., Pukite, J., Richter, A., van Roozendael, M., Rozanov, A., Rozanov, V., Sinreich, R., Sanghavi, S., and Wittrock, F.: Comparison of box-airmass-factors and radiances for Multiple-Axis Differential Optical Absorption Spectroscopy (MAX-DOAS) geometries calculated from different UV/visible radiative transfer models, Atmos. Chem. Phys., 7, 1809-1833, doi:10.5194/acp-7-1809-2007, 2007.
Wagner, T., Beirle, S., and Deutschmann, T.: Three-dimensional simulation of the Ring effect in observations of scattered sun light using Monte Carlo radiative transfer models, Atmos. Meas. Tech., 2, 113-124, doi:10.5194/amt-2-113-2009, 2009.

Wenig, M., Jähne, B., and Platt, U. : Operator Representation as a new differential optical absorption spectroscopy formalism, Appl. Optics, 44(16), 3246-3253, 2005.

Wilmouth, D. M., Hanisco, T. F., Donahue, N.M., and Anderson, J. G.: Fourier transform ultraviolet spectroscopy of the $\mathrm{A}^{2} \Pi_{3 / 2} \leftarrow$ $\mathrm{X}^{2} \Pi_{3 / 2}$ transition of BrO, J. Phys. Chem. 103, 8935-8945, 1999.

Yang, K., Krotkov, N. A., Krueger, A. J., Carn, S. A., Bhartia, P. K., and Levelt, P. F.: Retrieval of large volcanic $\mathrm{SO}_{2}$ columns from the Aura Ozone Monitoring Instrument: Comparison and limitations, J. Geophys. Res., 112, D24S43, doi:10.1029/2007JD008825, 2007.

Yang, K., Liu, X., Krotkov, N. A., Krueger, A. J., and Carn, S. A.: Estimating the altitude of volcanic sulfur dioxide plumes from space borne hyper-spectral UV measurements, Geophys. Res. Lett., 36, L10803, doi:10.1029/2009GL038025, 2009. 